\title{
Quantity Rationing of Credit
}

\author{
George A. Waters*† \\ Visiting Scholar \\ Research Department \\ Bank of Finland \\ and \\ Associate Professor \\ Department of Economics \\ Illinois State University
}

April 11, 2011

\begin{abstract}
Quantity rationing of credit, when firms are denied loans, has greater potential to explain macroeconomics fluctuations than borrowing costs. This paper develops a DSGE model with both types of financial frictions. A deterioration in credit market confidence leads to a temporary change in the interest rate, but a persistent change in the fraction of firms receiving financing, which leads to a persistent fall in real activity. Empirical evidence confirms that credit market confidence, measured by the survey of loan officers, is a significant leading indicator for capacity utilization and output, while borrowing costs, measured by interest rate spreads, is not.
\end{abstract}

Key Words: quantity rationing, credit, VAR

JEL Codes: E10, E24, E44, E50

\footnotetext{
*gawater@gmail.com

†The author thanks seminar participants at the Midwest Macroeconomics Meetings, the Bank of Finland, Illinois State University and the University of Piraeus for their comments and suggestions. The work is preliminary and all errors are my own. The views do not represent those of the Bank of Finland.
} 


\section{Introduction}

A recurrent theme in discussions about the interaction between financial markets and the macroeconomy ${ }^{1}$ is that borrowing costs do not fully reflect the availability of credit. While the development of DSGE macroeconomic models with financial frictions is proceeding rapidly, in most of these models the additional aggregate fluctuations from such frictions arise due to changes in the cost of financing, i.e. price rationing.

The present work develops a parsimonious DSGE model with quantity rationing of credit, where some firms may be denied loans, in addition to price rationing. Firms have heterogenous needs for working capital to pay their wage bills and must provide collateral in the form of current period cash flow. Credit market conditions are parameterized by the amount of collateral required by intermediaries. An exogenous increase in credit market stress leads to a temporary increase in interest rates, which has a modest effect on real activity, and a persistent decline in both the fraction of firms receiving financing and output.
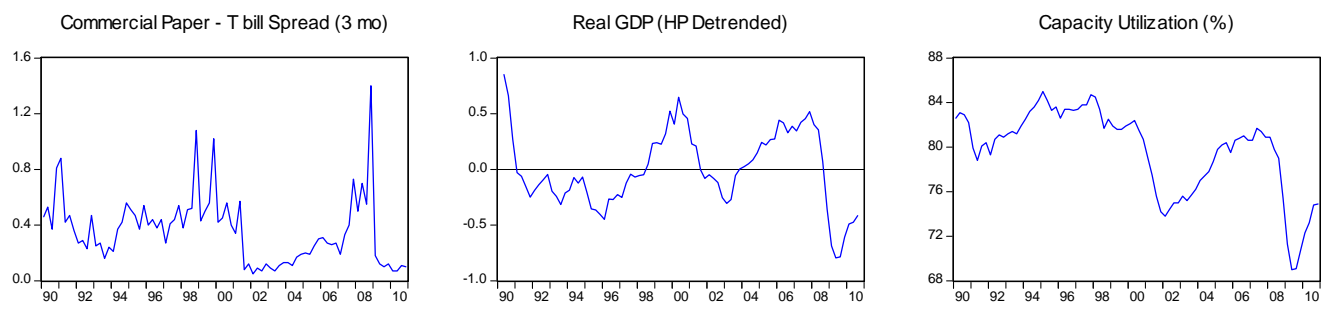

Graph 1: U.S. Data 1990Q2 - 2010Q4

The temporary increase in borrowing cost along with the persistent decline in aggregate real activity describes the U.S. experience (Graph 1) following the recent financial crisis. The spread between the three month commercial paper and Treasury bill rates, a measure of firm borrowing cost, peaked at $1.4 \%$ in the first quarter of 2009, but fell back to normal levels (below $0.2 \%$ ) in the next quarter. In contrast, capacity utilization and real GDP had made only a partial recovery a year later.

Results from VAR analysis confirm the relationships between aggregate and financial variables described in the theoretical model. The survey of bank managers by the New York Federal Reserve provides an empirical representation of credit market conditions, and capacity utilization is a proxy for the fraction of firms receiving financing. The measure of tightness of credit markets according to the survey of bank managers is negatively correlated with capacity utilization and real GDP for all specifications, while the role of borrowing costs is not quantitatively significant, strong evidence for the importance of quantity rationing.

The role of quantity rationing has been emphasized in the literature from a number of different perspectives. There is little empirical evidence for borrowing costs being important determinants of fluctuations 
in inventories and output (Kayshap and Stein 1993). Lown and Morgan (2006) provide evidence, using loan officer survey data, that lending standards are significantly correlated with aggregate lending and real output. The empirical approach here is related to their work, but with motivation from a DSGE model. Theoretical models also demonstrate the importance of quantity rationing. Boissay (2001) shows that quantity rationing acts as a significant financial accelerator of fluctuations in a real business cycle model. The model presented here borrows some modeling language from his approach.

A number of papers develop DSGE models that include financial intermediaries whose lending is constrained by frictions arising from agency restrictions such as net worth (Carlstrom and Fuerst 1997, Bernanke, Gertler and Gilchrist 1996), monitoring costs (Bernanke and Gertler 1989) or collateral constraints (Monacelli 2009). Faia and Monacelli (2007) is related in that firm borrowing is affected by idiosyncratic shocks. In their approach, the monitoring costs vary across firms and only a fraction of intermediaries participate, while in the present work there is a representative intermediary and a fraction of firms receives financing. Recently, Gertler and Kiyotaki (2011) and Gertler and Karadi (2009) have developed models based on the net worth approach that allow lending between intermediaries and a binding zero lower bound on policy rates, where policies such as quantitative easing are viable options for responding to a financial crisis.

The financial frictions in the work referenced here all take the form of price rationing. Some of these approaches are able to model financial crises such as fire sales of assets and disruptions of lending between intermediaries that lead to large falls in real activity. However, financial market frictions affect the behavior of households and firms through higher interest rates or spreads. Furthermore, the magnitude and persistence of the decline in real activity is matched by that of the increase in borrowing $\operatorname{costs}^{2}$ in these models, which is not the usual pattern in recessions driven by financial factors.

The paper is organized as follows. Section 2 describes the model, focusing on the working capital requirement. Section 3 derives the implication of the model for aggregate variables. Section 4 describes a calibration and simulation exercise with the model. Section 5 gives the results of the empirical analysis and Section 6 concludes.

\section{Model}

The formulation of the model focuses on the role of quantity rationing of credit. The decision of the representative household is standard, and the primary innovation of the model is the heterogeneity of firms in the portion of their wage bill that must be financed, embodied in the variable $v_{t}$ which has distribution $F\left(v_{t}\right)$ over $[0,1]$. This variable could represent differences in firms' internal financial resources or the timing of their cash flows. If a firm is unable to get financing, it does not produce that period ${ }^{3}$. An individual 
firm with draw $v_{t}$, has financing need $\phi\left(v_{t}\right)=W_{t} l\left(v_{t}\right) v_{t}$ where $W_{t}$ is the real wage, and $l\left(v_{t}\right)$ is the labor demand for a producing firm. Firms are wage takers so $W_{t}$ is the real wage for all firms. If the firm gets financing, it produces output $y_{t}\left(v_{t}\right)=a_{t} l_{t}\left(v_{t}\right)^{\alpha}$ where $a_{t}$ is the level of productivity and the parameter $\alpha$ takes values between zero and one.

Firms cannot commit to repayment of loans and so must provide collateral in the form of period $t$ output. The collateral condition is $\tau^{-1} y_{t}\left(v_{t}\right) \geq\left(1+r_{t}\right) \phi\left(v_{t}\right)$ where the real interest rate is $r_{t}$ and the parameter $\tau^{-1}$ is the fraction of output the intermediary accepts as collateral. The productivity shock $a_{t}$ and need for financing $v_{t}$ are both realized at the beginning of period $t$, so the intermediary does not face any uncertainty in the lending decision. Substituting for $y_{t}\left(v_{t}\right)$ and $\phi\left(v_{t}\right)$ yields the following form for the collateral requirement.

$$
\tau^{-1} a_{t} l_{t}\left(v_{t}\right)^{\alpha} \geq\left(1+r_{t}\right) W_{t} l_{t}\left(v_{t}\right) v_{t}
$$

The parameter $\tau$ represents the aggregate credit market stress embodied in the collateral requirements made by banks and firms' ability to meet them. A sudden fall in confidence, i.e. a disturbance of animal spirits, such as the collapse of the commercial paper market in the Fall of 2008, could be represented by an exogenous rise $^{4}$ in $\tau$. Explicitly modeling changes in $\tau$ may be desirable, but the focus of the present paper is to demonstrate the connection between credit market conditions and real economic activity.

Profit for an individual firm with realization $v_{t}$ for its financing need is the following.

$$
\Pi_{t}\left(v_{t}\right)=a_{t} l_{t}\left(v_{t}\right)^{\alpha}-W_{t} l_{t}\left(v_{t}\right)-r_{t} W_{t} l_{t}\left(v_{t}\right) v_{t}
$$

Hence, labor demand for the firm is

$$
\alpha a_{t} l_{t}\left(v_{t}\right)^{\alpha-1}=W_{t}\left(1+r_{t} v_{t}\right) .
$$

Using the labor demand relation, the collateral constraint (1) becomes $\tau^{-1}\left(1+r_{t} v_{t}\right) \geq \alpha\left(1+r_{t}\right) v_{t}$. From this condition, we can define $\bar{v}_{t}$, the maximum $v_{t}$ above which firms cannot produce. For firms to produce in period $t$, they must have a $v_{t}$ such that

$$
v_{t} \leq \bar{v}_{t}=\min \left\{1,\left[\tau \alpha\left(1+r_{t}\right)-r_{t}\right]^{-1}\right\} .
$$

Note that the fraction of firms producing $\bar{v}_{t}$ is decreasing in the credit market stress parameter $\tau$. At an interior value for $\bar{v}_{t}<1$, it must be the case that $\tau \alpha>1$, which implies that the fraction of firms producing is decreasing in the interest rate. 
Since the fraction of firms receiving financing $\bar{v}_{t}$ is decreasing in the interest rate and does not respond directly to other endogenous variables, it does not provide an accelerator mechanism for a shock to productivity. This observation is a result of the particular form of equation (3). There are many alternative specifications where labor demand or other endogenous quantities would enter, see Boissay (2001) for example. Using such an alternative to model a financial accelerator mechanism is quite possible, but a full investigation is left for future work.

The household chooses optimal levels of consumption $C_{t}$, labor supplied $L_{t}$ and deposits (savings) $D_{t}$.

$$
\begin{gathered}
\max _{C_{t}, L_{t}, D_{t}} E_{0} \sum_{t=0}^{\infty} \beta^{t}\left[\frac{C_{t}^{1-\sigma}}{1-\sigma}-\chi \frac{L_{t}^{1+\eta}}{1+\eta}\right] \quad \text { subject to } \\
C_{t}+D_{t} \leq\left(1+r_{t}\right) D_{t}+W_{t} L_{t}+\int_{0}^{\bar{v}_{t}} \Pi_{t} d F\left(v_{t}\right)+G_{t}
\end{gathered}
$$

Households hold shares in all firms and receive profits from producing firms $\int_{0}^{\bar{v}_{t}} \Pi_{t} d F\left(v_{t}\right)$. They also receive profits $G_{t}$ from the intermediary where $G_{t}=D_{t}-D_{t}\left(1+r_{t}\right)+r_{t} \phi_{t}^{e}$. Households borrow $D_{t}$ at the beginning of period $t$ and repay $\left(1+r_{t}\right) D_{t}$ at the end. The timing specified here is common ${ }^{5}$ in models with a financial sector, and is chosen to have an intuitive form for the consumption Euler equation. The household is assumed to insure against labor market fluctuations internally, as in Gertler and Karadi (2009), for one example. The term $\phi_{t}^{e}$ is the aggregate amount of lending to firms, which is

$$
\phi_{t}^{e}=\int_{0}^{\bar{v}_{t}} W_{t} l\left(v_{t}\right) v_{t} d F\left(v_{t}\right)
$$

The aggregate levels of output $Y_{t}$ and labor $L_{t}$ also depend on the fraction of firms producing.

$$
\begin{aligned}
Y_{t} & =a_{t} \int_{0}^{\bar{v}_{t}} l_{t}\left(v_{t}\right)^{\alpha} d F\left(v_{t}\right) \\
L_{t} & =\int_{0}^{\bar{v}_{t}} l_{t}\left(v_{t}\right) d F\left(v_{t}\right)
\end{aligned}
$$

First order conditions from the household optimization problem yield standard consumption Euler and labor-leisure relations.

$$
\begin{aligned}
1 & =\beta\left(1+r_{t}\right) E_{t}\left[\left(\frac{C_{t}}{C_{t+1}}\right)^{\sigma}\right] \\
W_{t} & =\chi L_{t}^{\eta} C_{t}^{\sigma}
\end{aligned}
$$

It is now possible to define the equilibrium given by the above model for the endogenous vector $X_{t}=$ 
$\left\{Y_{t}, y_{t}\left(v_{t}\right), L_{t}, l_{t}\left(v_{t}\right), C_{t}, r_{t}, \bar{v}_{t}, W_{t}, D_{t}, \phi_{t}^{e}\right\}$. The key equations are labor demand (2), aggregate output (6), aggregate lending $\phi_{t}^{e}$ (5), aggregate labor (7), labor supply (9) and the consumption Euler equation (8). For the goods market to clear, the relation $Y_{t}=C_{t}$ must hold. Also, deposits equal aggregate lending to firms $D_{t}=\phi_{t}^{e}$ and financial intermediaries have zero profit in equilibrium $G_{t}=0$. The above equations yield steady state values $\widetilde{X}$ for a given level of productivity $\widetilde{a}$, or a rational expectations equilibrium sequence $\left\{X_{t}\right\}$ for a specification of $a_{t}$.

\section{Aggregate Output and Labor}

The goal of this section is to establish the connection between aggregate output and the financial elements of the model. For a fixed real wage, output is increasing in $\bar{v}_{t}$ and decreasing in $r_{t}$. When labor supply is taken into account, the intuition is the same though some parameter restrictions are necessary. Propositions about the response of steady state aggregate output are to changes in financial factors are given.

The first task is to aggregate over $v_{t}$, which represents the varying financing needs of the firms. Assume that $v_{t}$ is uniformly distributed on $[0,1]$, such that and $F\left(v_{t}\right)=v_{t}$. Using the labor demand equation (2) to substitute for $l_{t}\left(v_{t}\right)$, and integrating equation (7) yields the quantity of aggregate labor

$$
L_{t}=\left(\frac{1-\alpha}{\alpha}\right)\left(\frac{W_{t}}{\alpha a_{t}}\right)^{\frac{-1}{1-\alpha}} r_{t}^{-1}\left[1-\left(1+r_{t} \bar{v}_{t}\right)^{\frac{-\alpha}{1-\alpha}}\right]
$$

The above shows the usual labor demand relation in that it is decreasing in the real wage. An increase in $\bar{v}_{t}$ due to a decrease in the credit market stress parameter $\tau$, would shift labor demand up. A higher $\bar{v}_{t}$ implies that firms with greater financing needs and higher marginal costs are producing. However, this effect is outweighed by the increased amount of firms producing which increases the demand for labor.

Similarly, the aggregate output relation (6) along with labor demand (2) can be solved.

$$
Y_{t}=\left(\frac{1-\alpha}{2 \alpha-1}\right) a_{t}\left(\frac{W_{t}}{\alpha a_{t}}\right)^{\frac{-\alpha}{1-\alpha}} r_{t}^{-1}\left[1-\left(1+r_{t} \bar{v}_{t}\right)^{-\left(\frac{2 \alpha-1}{1-\alpha}\right)}\right]
$$

Choosing labor's share of output $\alpha$ to be greater than one-half is standard so, given a fixed real wage $W_{t}$, output $Y_{t}$ is increasing in $\bar{v}_{t}$. For a give real wage, aggregate output and labor are decreasing in the interest rate for natural parameter values.

The equations for labor supply (9), aggregate labor demand (10). aggregate output (11) and the goods market clearing condition $Y_{t}=C_{t}$ show that equilibrium $Y_{t}, L_{t}$ and $W_{t}$ may be written in terms of the 
variables $r_{t}$ and $\bar{v}_{t}$. To examine the dynamics, the Euler equation $1=\beta\left(1+r_{t}\right) E_{t}\left[\left(\frac{Y_{t}}{Y_{t+1}}\right)^{\sigma}\right]$ also plays an important role, though it also implies that the steady state interest rate is dependent only on the discount factor $\widetilde{r}=\beta^{-1}$. Only a change in the discount rate $\beta$ can have a persistent effect on the interest rate under rational expectations.

To model the impact of a financial crisis, we examine the effect of an exogenous increase in credit market stress embodied by $\tau$. Similar experiments are done as a shock to intermediary net worth in Gertler and Karadi (2009) and capital quality in Gertler and Kiyotaki (2011). An alternative approach would be to examine an exogenous decline in the discount factor leading to an increase in the steady state interest rate, but the effect of such a change on real activity would be modest and the goal is to show a persistent effect without relying on a persistent change in borrowing costs ${ }^{6}$. The following proposition examines the change in steady state output due to a change in $\tau$.

Proposition 1 For the model defined by equations (3), (8), (9), (10), and (11), given $\alpha>1 / 2$ and an interior solution for $\bar{v}_{t}<1$, the steady state quantity of output $\tilde{Y}$ is decreasing in $\tau$ for $\eta>0$ sufficiently small.

Proof. See Appendix

An increase in credit market stress leads to more quantity rationing and reduced output. The restriction on $\eta$ is necessary, since for highly inelastic labor supply, the large change in the wage associated with a change in $\tau$ dampens the impact on production. The restriction is met for all calibrations in the literature.

Proposition 1 represents a departure from other DSGE models with a unique steady state in that a persistent change in a parameter representing credit market conditions causes a persistent change in real activity independent of borrowing costs. In other words, the equilibrium level of output and labor could fall solely due to an increase in quantity rationing of credit as opposed to price rationing. Financial frictions can directly impact real activity through changes in the fraction of firms receiving financing $\bar{v}_{t}$.

Price rationing remains a factor in the determination of real activity.

Proposition 2 For the model defined by equations (3), (8), (9), (10), and (11), for $0<\alpha<1$ and $\eta>0$ sufficiently small, steady steady state levels of output $\widetilde{Y}$ and the interest rate $\widetilde{r}$ are inversely related.

Proof. See appendix

Higher borrowing costs lower production. The parameter restrictions are satisfied for usual calibrations. For a given level of expected output, the Euler equation (8) also has an inverse relationship between output and the interest rate, so the intuition of Proposition 2 extends to equilibrium values. However, unless there 
is a change in the discount factor, the change in the interest rate is only temporary, since it returns to its steady state value once expectations adjust.

The model provides an avenue for distinguishing the effects of changes in credit standards from those of changes in interest rates, which reflect multiple factors independent of the relationship between financial intermediaries and producers. A primary goal of the simulation and empirical exercises is to compare the quantitative importance of price and quantity rationing. In its present form, the model does not produce the gradual adjustment to shocks seen in the data, but it does provide recommendations on the relationships between aggregate variables, such as output $Y_{t}$ and capacity utilization $\bar{v}_{t}$, and financial factors $\tau$ and $r_{t}$. Such a simple form for the dynamics is chosen to demonstrate the roles of quantity and price rationing. Evidence from VARs verifies the connection between the variables in the model and provides guidance on the best approaches for further development of related models.

\section{Calibration and Simulation}

A calibration of the model allows a brief analysis of the short run dynamics following a shock to credit market stress. Though the qualitative dynamics are well described in Proposition 1, the model is not static due to the presence of the consumption Euler equation (8). The choices $\alpha=2 / 3$ and $\eta=5.0$ are standard (Gali 2011). In the literature, the utility function parameter $\sigma$ takes a wide range of values, and we set it to 0.5 , so that the steady state level of labor has an intuitive response to changes in $\tau$. The steady state level of the interest rate $\widetilde{r}$ is set to 0.03 , which implies a discount factor of $\beta=1.03^{-1}$.

The choice of $\tau$ parameterizing credit market stress is set to obtain a reasonable steady state value of the fraction of firms receiving financing. Given the choices above for $\alpha$ and $\widetilde{r}$, the parameter $\tau$ is chosen so that $\widetilde{\bar{v}}=0.8$, which corresponds to the mean level of capacity utilization in the U.S. over the past two decades. The steady state level of output $\widetilde{Y}$ is normalized to one, and the steady state $\widetilde{L}$ is set to 0.62 in line with the labor participation rate in the U.S. (Gali 2011). These steady state choices determine the steady state level of productivity $\widetilde{a}=1.48159$ and the utility function parameter $\chi=11.5994$.

Figures 1-4 show the response of $Y_{t}, L_{t} r_{t}$ and $\bar{v}_{t}$ to a surprise, exogenous shift in $\tau$. The credit market parameter $\tau$ rises such that the steady state fraction of firms receiving financing falls by 0.1 , corresponding to the drop in capacity utilization from 0.8 to 0.7 following the financial crisis. In the first period, the interest rate adjusts since expected output does not change with a surprise shock, and households attempt to smooth consumption. The subsequent periods are governed by the changes in the steady state given in Proposition 1. Such a shift in $\tau$ would not necessarily be permanent, and the analysis applies to short to medium term dynamics following such a change. 
An important feature of the graphs is the one period spike in the interest rate, followed by its return to the steady state level. What is notable is the magnitude of the change, equivalent to more than 200 basis points, and its limited effect on the other variables, which display very modest overshooting as a result of the interest rate change. In contrast, the fall output is large and persistent, and the $4 \%$ fall matches the recent recession reasonably well. A persistent shock to credit market stress can lead to a persistent response in output and labor but a temporary change in the real interest rate, as observed following the recent crisis.

\section{$5 \quad$ Empirical Results}

Results from VARs confirm the relationship between the variables indicated by the theoretical model. Credit market tightness, as measured by the survey of bank managers, Granger causes capacity utilization and real GDP, and examination of variance decomposition verifies that credit market tightness is a more important factor than borrowing costs.

The sample 1990Q2-2010Q4 for U.S. data is chosen to match the most recent continuous reporting of the survey of bank managers by the Federal Reserve Bank of New York. The variable TIGHT refers to the net fraction of respondents reporting a tightening of lending standards over the last quarter, so it represents a measure a credit market stress. Lown and Morgan (2006) discuss the survey in detail and conduct a VAR analysis ${ }^{7}$ as well, though their choice of model is made for comparison with related empirical studies. The estimations use log transformations of real gross domestic product and output per hour, a productivity measure, to construct RGDP and OPH. The spread between the BAA corporate rate and the 10 year treasury (BAATEN) is the measure of real firm borrowing cost used in the reported estimations, and the spread between the three month commercial paper and Treasury bill rates are used as a robustness $\operatorname{check}^{8}$. The model specified in Proposition 1 does not give strong predictions about the dynamic interactions between the variables so, there are no structural restrictions.

The equation (3) for $\bar{v}_{t}$ indicates that capacity utilization should depend on credit market stress, represented by $\tau$, and the real interest rate, so the first empirical exercise is a VAR estimation with CAPUT, BAATEN and TIGHT in that order. Table 1 shows results for a test of Granger causality for this system ${ }^{9}$ and Figure 5 shows the impulse response functions for a generalized impulse ${ }^{10}$ to each variable.

Credit market tightness (stress) leads to a fall in capacity utilization. Both the Granger causality and impulse response functions demonstrate that lending standards are a leading indicator of both capacity utilization and the interest rate spread, while other relationships cannot be reliably established. In particular, the interest rate spread does not cause ${ }^{11}$ capacity utilization confirming the conjecture that credit market stress parameterized by $\tau$ in the theoretical model is the primary driver of $\bar{v}_{t}$. Figure 6 shows the variance 
decompositions and demonstrates the explanatory value of the measure of credit market stress even more strongly, with over $50 \%$ of the variance of capacity utilization explained by TIGHT after 4 lags and over $85 \%$ after 8 lags. Different orderings of the variables do not change the results qualitatively. The estimation verifies the connection between capacity utilization and credit market stress in the theoretical model, but shows that the timing is more complicated, and credit market stress is a leading indicator among these variables.

Credit market conditions are a leading indicator for output as well. One can use equations (9), (10) and (11) to solve for $Y_{t}$ as a function of the financial variables, though productivity represented by $a_{t}$ is always present as well. Therefore, we estimate a VAR with RGDP, OPH, BAATEN and TIGHT. Table 2 and Figure 7 show the Granger causality tests and impulse response functions.

As with the previous results, credit market stress causes all the other variables and shows a strong lagged effect on real GDP in the impulse response functions. The spread BAATEN is correlated with RGDP as well, though at a lower level of significance. Further analysis of the variance decomposition graphs in Figure 8 demonstrate the importance of credit market stress, particularly with respect to its explanatory power for RGDP, which is over $50 \%$ for lags greater than four. In contrast, innovations in the spread do not account for any significant amount of the variance in RGDP. As with the capacity utilization estimation, credit market stress has explanatory power for the spread, but this result does not hold for shorter maturities.

The conclusion that credit market conditions are correlated with real activity independent of other factors is in agreement with the results in Lown and Morgan (2006). The impact of credit market conditions on output is not a reflection of productivity shocks. Productivity (OPH) and RGDP cause each other, but OPH does cause either BAATEN or TIGHT. In fact, TIGHT causes OPH (Table 2 and Figure 7), so credit market stress is an important, independent determinant of RGDP. Regressions without OPH give qualitatively similar results. Furthermore, credit market stress affects output independent of borrowing costs. Results of VARs without TIGHT have similar impulse responses and variance decompositions for the effect of BAATEN on RGDP.

The result that a deterioration of credit market conditions leads to a decline in real activity is robust to a variety of alternative specifications, including the use of non-detrended data and hours worked as a measure a real activity. Lown and Morgan (2006) use the spread between interest rates on commercial paper and Treasury bills as a measure of borrowing costs. A similar measure shows no correlation with the other variables when used in regressions like those reported here, further evidence of the relative unimportance of borrowing costs. While the timing of the interactions is much more complex than suggested by the theoretical model, the empirical results confirm the importance of credit market stress as a determinant of macroeconomic fluctuations. 
A question that arises in discussions of the impact of bank lending on GDP on other aggregate variables is whether changes are driven by loan supply or demand. The results here suggest that loan supply is most important, in agreement with Kayshap and Stein (1993) and Kayshap, Stein and Wilcox (1994). If output and lending decline due to a demand shock such as a shock to business confidence, the interest rate would be expected to fall with the demand for loans. However, the impulse responses in Figures 7 and 11 show that a fall in RGDP is associated with a rise in the cost of borrowing to firms, and both are caused by a tightening of lending standards. Furthermore, according the variance decomposition results in Figure 8, RDGP does not have significant explanatory power with respect to BAATEN. Hence, a restriction in the supply of loans is the most important financial factor to explain a decline in output.

\section{Conclusion}

The importance of financial frictions to macroeconomic fluctuations is undeniable, but the channel though which they operate and the proper approach to modeling them are still difficult issues. While interest rates and borrowing costs are important, there is evidence that they are not the primary factor. The present paper offers a formal approach to quantity rationing of credit, where a loss of confidence on the part of lenders or the inability of borrowers to provide collateral can lead to a denial of loans to some firms with a direct impact on output and employment. While the role of the resulting fluctuations due to the interest rate is temporary and small, quantity rationing can explain large changes in real activity.

Empirical analysis where the credit market stress is represented by data from the survey of bank managers confirms the relationship between aggregate activity and financial variables described by the model. The tightness of credit markets is a leading indicator of both capacity utilization and real GDP, while measures of

borrowing costs play a minor role. Since capacity utilization and real GDP have modest and inverse causal impact (if any) on interest rate spreads, the VAR analysis provides evidence of the primary importance of fluctuation in loan supply as opposed to demand.

There are many potential extensions of the present model. Besides the inclusion of more dynamic elements, a more detailed description of the determinants of credit market conditions may also be desirable. However, even in its present parsimonious form, the model demonstrates that quantity rationing of credit provides a natural explanation for large aggregate fluctuations. 


\section{Appendix}

The proof of Proposition 1 makes use of the following steady state relations from equations (8), (3), (9),

(7) and (11).

$$
\begin{aligned}
\widetilde{r} & =\beta^{-1}-1 \\
\widetilde{v} & =\min \left\{1,[\tau \alpha(1+\widetilde{r})-\widetilde{r}]^{-1}\right\} \\
\widetilde{W} & =\chi \widetilde{L}^{\eta} \widetilde{C}^{\sigma} \\
\widetilde{L} & =\left(\frac{1-\alpha}{\alpha}\right)\left(\frac{\widetilde{W}}{\alpha \widetilde{a}}\right)^{\frac{-1}{1-\alpha}} \widetilde{r}^{-1}\left[1-(1+\widetilde{r} \bar{v}) \frac{-\alpha}{1-\alpha}\right] \\
\widetilde{Y} & =\left(\frac{1-\alpha}{2 \alpha-1}\right) a\left(\frac{\widetilde{W}}{\alpha \widetilde{a}}\right)^{\frac{-\alpha}{1-\alpha}} \widetilde{r}^{-1}\left[1-(1+\widetilde{r} \widetilde{v})^{\left.-\left(\frac{2 \alpha-1}{1-\alpha}\right)\right]}\right]
\end{aligned}
$$

The proof of Proposition 1:

Proof. Since $\frac{d \widetilde{r}}{d \tau}=0, \frac{d \widetilde{\bar{v}}}{d \tau}=-\widetilde{\bar{v}}^{2} \alpha \beta^{-1}<0$ for an interior solution to $\widetilde{\bar{v}}$.

Differentiating the steady state labor supply relation using the goods clearing relation $\widetilde{C}=\widetilde{Y}$ yields

$$
\frac{d \widetilde{W}}{d \tau}=\eta \frac{\widetilde{W}}{\widetilde{L}} \frac{d \widetilde{L}}{d \tau}+\sigma \frac{\widetilde{W}}{\widetilde{L}} \frac{d \widetilde{Y}}{d \tau}
$$

Differentiating the labor demand relation and combining it with the above yields the following.

$$
\frac{d \widetilde{L}}{d \tau}\left(1+\frac{\eta}{1-\alpha}\right)=\left(\frac{-\sigma}{1-\alpha}\right) \frac{\widetilde{L}}{\widetilde{Y}} \frac{d \widetilde{Y}}{d \tau}+\left(\frac{\alpha}{1-\alpha}\right)\left(\begin{array}{c}
(1+\widetilde{r} \widetilde{\bar{v}}) \frac{-1}{1-\alpha} \\
1-(1+\widetilde{r} \tilde{\bar{v}}) \frac{-\alpha}{1-\alpha}
\end{array}\right) \widetilde{L} \widetilde{r} \frac{d \bar{v}}{d \tau}
$$

A similar manipulation of the aggregate output equation yields the following.

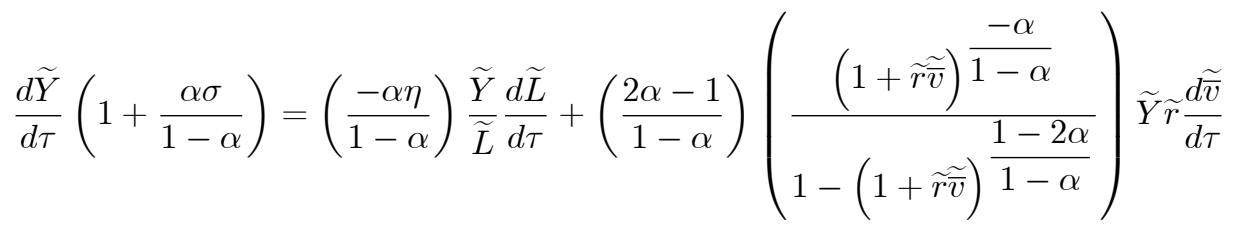


Solving for $\frac{d \widetilde{Y}}{d \tau}$.

$$
\begin{aligned}
& \frac{d \widetilde{Y}}{d \tau}(1-\alpha)\left(\frac{1-\alpha}{\eta}+1\right)=\tilde{Y} \widetilde{r} \frac{d \widetilde{\bar{v}}}{d \tau}(2 \alpha-1)\left(\frac{1-\alpha}{\eta}+1\right)\left(\frac{(1+\widetilde{r} \tilde{\bar{v}}) \frac{-1}{1-\alpha}}{1-\left(1+\widetilde{r} \widetilde{\bar{v}} \frac{-\alpha}{1-\alpha}\right.}\right) \\
& -\widetilde{Y} \widetilde{r} \frac{d \widetilde{v}}{d \tau} \alpha^{2}\left(\frac{(1+\widetilde{r} \widetilde{\bar{v}}) \frac{-\alpha}{1-\alpha}}{1-(1+\widetilde{r} \tilde{\bar{v}})^{\frac{1-2 \alpha}{1-\alpha}}}\right)
\end{aligned}
$$

Note that for $1 / 2<\alpha<1$, all the terms in parenthesis in the above equations are positive. For $\eta$ sufficiently small, the first term on the right hand side of the equation for $\frac{d \widetilde{Y}}{d \tau}$ dominates, and $\frac{d \widetilde{Y}}{d \tau}<0$, as required.

The proof of Proposition 2 has a similar structure:

Proof. Differentiating the steady state labor supply relation using the goods clearing relation $\widetilde{C}=\widetilde{Y}$ yields

$$
\frac{d \widetilde{W}}{d \widetilde{r}}=\eta \frac{\widetilde{W}}{\widetilde{L}} \frac{d \widetilde{L}}{d \widetilde{r}}+\sigma \frac{\widetilde{W}}{\widetilde{L}} \frac{d \widetilde{Y}}{d \widetilde{r}}
$$

Differentiating the labor demand relation and combining it with the above yields the following.

$$
\frac{d \widetilde{L}}{d \widetilde{r}}\left(1+\frac{\eta}{1-\alpha}\right)=\left(\frac{-\sigma}{1-\alpha}\right) \frac{\widetilde{L}}{\widetilde{Y}} \frac{d \widetilde{Y}}{d \widetilde{r}}-\frac{\widetilde{L}}{\widetilde{r}}+\left(\frac{\alpha}{1-\alpha}\right)\left(\frac{(1+\widetilde{r} \bar{v})^{\frac{-1}{1-\alpha}}}{1-(1+\widetilde{r} \overline{\bar{v}})^{\frac{-\alpha}{1-\alpha}}}\right) \widetilde{L}\left(\widetilde{\bar{v}}+\widetilde{r} \frac{d \widetilde{\bar{v}}}{d \widetilde{r}}\right)
$$

A similar manipulation of the aggregate output equation yields the following.

$$
\frac{d \widetilde{Y}}{d \widetilde{r}}\left(1+\frac{\alpha \sigma}{1-\alpha}\right)=\left(\frac{-\alpha \eta}{1-\alpha}\right) \frac{\widetilde{Y}}{\widetilde{L}} \frac{d \widetilde{L}}{d \widetilde{r}}-\frac{\widetilde{Y}}{\widetilde{r}}+\left(\frac{2 \alpha-1}{1-\alpha}\right)\left(\frac{(1+\widetilde{r} \widetilde{\bar{v}}) \frac{-\alpha}{1-\alpha}}{1-(1+\widetilde{r} \overline{\bar{v}}) \frac{1-2 \alpha}{1-\alpha}}\right) \widetilde{Y}\left(\widetilde{\bar{v}}+\widetilde{r} \frac{d \widetilde{\bar{v}}}{d \widetilde{r}}\right)
$$


Solving for $\frac{d \widetilde{Y}}{d \widetilde{r}}$.

$$
\begin{aligned}
\frac{d \widetilde{Y}}{d \widetilde{r}}\left[1+\frac{\sigma \alpha(1-\alpha)}{(1-\alpha)(1-\alpha+\eta)}\right]= & \frac{\alpha \eta}{1-\alpha+\eta} \widetilde{L}\left[\frac{1}{\widetilde{r}}-\left(\frac{\alpha}{1-\alpha}\right)\left(\widetilde{\bar{v}}+\widetilde{r} \frac{d \widetilde{\bar{v}}}{d \widetilde{r}}\right) \frac{(1+\widetilde{r} \bar{v}) \frac{-1}{1-\alpha}}{1-\left(1+\widetilde{r} \widetilde{\bar{v}} \frac{-\alpha}{1-\alpha}\right.}\right] \\
& -\widetilde{Y}\left[\frac{1}{\widetilde{r}}-\left(\frac{2 \alpha-1}{1-\alpha}\right)\left(\widetilde{\bar{v}}+\widetilde{r} \frac{d \widetilde{\bar{v}}}{d \widetilde{r}}\right) \frac{(1+\widetilde{r} \overline{\bar{v}}) \frac{-1}{1-\alpha}}{1-(1+\widetilde{r} \tilde{\bar{v}}) \frac{-\alpha}{1-\alpha}}\right]
\end{aligned}
$$

For $\eta$ sufficiently small, the second term $\widetilde{Y}[\cdot]$ on the right hand side of the equation for $\frac{d \widetilde{Y}}{d \widetilde{r}}$ dominates. The expression $\widetilde{\bar{v}}+\widetilde{r} \frac{d \widetilde{\bar{v}}}{d \widetilde{r}}$ is such that $\widetilde{\bar{v}}+\widetilde{r} \frac{d \widetilde{\bar{v}}}{d \widetilde{r}}=\frac{\tau \alpha}{[\tau \alpha(1+\widetilde{r})-\widetilde{r}]^{2}}$ for an interior solution of $\widetilde{\bar{v}}$. For an interior solution it must be the case that $\tau \alpha>1$, so $\widetilde{\bar{v}}+\widetilde{r} \frac{d \bar{v}}{d \widetilde{r}}$ is decreasing in $\tau$ and bounded above by 1 . The expressions $\frac{(1+\tilde{r} \tilde{\bar{v}}) \frac{-1}{1-\alpha}}{1-(1+\tilde{r} \tilde{\bar{v}}) \frac{-\alpha}{1-\alpha}}=\left[(1+\widetilde{r} \bar{v}) \frac{1}{1-\alpha}+(1+\widetilde{r} \bar{v})\right]^{-1}$, and $\frac{2 \alpha-1}{1-\alpha}$ are both increasing in $\alpha$, and for any positive bound $\varepsilon$, there exists and $\alpha$ small enough so that $\left(\frac{2 \alpha-1}{1-\alpha}\right)\left(\widetilde{\widetilde{v}}+\widetilde{r} \frac{d \widetilde{\bar{v}}}{d \widetilde{r}}\right) \frac{(1+\widetilde{r} \overline{\bar{v}}) \frac{-1}{1-\alpha}}{1-(1+\widetilde{r} \widetilde{v}) \frac{-\alpha}{1-\alpha}}>\varepsilon$. Therefore, for $\alpha$ and $\eta$ sufficiently small, $\frac{d \widetilde{Y}}{d \widetilde{r}}<0$, as required. 


\section{Notes}

${ }^{1}$ Lown and Morgan (2006) have an extended section on the topic and quote Blanchard and Fisher (1989). Stiglitz and Weiss (1981) give a theoretical basis for credit rationing, though for different reason than those in the present work.

${ }^{2}$ Kiyotaki and Moore (2008) is a related paper where liquidity shocks have a temporary effect on asset returns, though this work is preliminary.

${ }^{3} \mathrm{~A}$ more realistic assumption would be that some firms or portions of firms always get financing. The present choice is made for simplicity.

${ }^{4}$ Similarly, Gertler and Kiyotaki (2010) model the start of a crisis as a deterioration of the value of assets held by financial intermediaries.

${ }^{5}$ For example, see Christiano and Eichenbaum (1992) and Ravenna and Walsh (2006).

${ }^{6} \mathrm{An}$ increase in the the discount factor combined with the zero lower bound on the nominal interest rate can lead to a substantial fall in output, see Christiano, Eichenbaum and Rebelo (2009).

${ }^{7}$ Jacobson, Linde and Roszbach (2005) also do an empirical analysis of the interaction between financial and macro variables using VARs, among other techniques. They construct a measure of the frequency of bankruptcies for Sweden in the 1990s.

${ }^{8}$ Lown and Morgan use this spread at a maturity of six month, which is not available for the sample in the present work.

${ }^{9}$ The lag length criteria statistics recommend the use of one or two lags, but estimations of such systems have serially correlated residuals so all the estimations reported here have 4 or 8 lags, appropriate for quarterly data.

${ }^{10}$ Except for the survey of bank managers all data available from the Federal Reserve Bank of St. Louis. The specification for the generalized impulse responses, which are independent of the ordering of the variables, is due to Peseran and Shin (1989).

${ }^{11}$ In this section, the word "causes" always refers to Granger causality.

\section{References}

Ben Bernanke and Mark Gertler (1989). "Agency Costs, Net Worth and Business Fluctuations." American Economic Review 79(1), 14-31.

Ben Bernanke, Mark Gertler and Simon Gilchrist (1996). "The Financial Accelerator in a Quantitative Business Cycle Framework." in The Handbook of Macroeconomics 1(1), edited by John Taylor and Michael Woodford, pp. 1341-1393, Elsevier, Amsterdam.

Olivier Blanchard and Stanley Fisher (1989). Lectures on Macroeconomics. Cambridge, MA.: MIT Press.

Federic Boissay (2001). "Credit Rationing, Output Gap, and Business Bycles." European Central Bank Working Paper 87.

Charles Carlstrom and Timothy Fuerst (1997). "Agency Costs, Net Worth, and Business Fluctuations: A Computable General Equilibrium Analysis," American Economic Review 87(5), 893-910.

Lawrence J. Christiano and Martin Eichenbaum (1992). "Liquidity Effects and the Monetary Transmission 
Mechanism." American Economic Review 82(2), 346-353.

Lawrence J. Christiano, Martin Eichenbaum and Sergio Rebelo (2009). "When is the Government Spending Multiplier Large." National Bureau of Economics Research Working Paper 15394.

Ester Faia and Tommaso Monacelli (2007). "Optimal Interest Rate Rules, Asset Prices, and Credit Frictions." Journal of Economic Dynamics and Control 31(10), 3228-3254.

Jordi Gali (2011). "Monetary Policy and Unemployment." in The Handbook of Monetary Economics 3A, edited by B. Friedman and M. Woodford pp. 487-546, Elsevier.

Mark Gertler and Peter Karadi (2009). "A Model of Unconventional Monetary Policy, manuscript.

Marik Gertler and Nobuhiro Kiyotaki (2011). "Financial Intermediation and Credit Policy in Business Cycle Analysis, The Handbook of Macroeconomics (forthcoming), Elsevier, Amsterdam.

Tor Jacobson, Jesper Linde and Karl Roszbach (2004). "Exploring Interactions Between Real Activity and the Financial Stance." Sveriges Riksbank Working Paper 184.

Cara Lown and Donald Morgan (2006). "The Credit Cycle and the Business Cycle: New Findings Using the Loan Officer Opinion Survey." Journal of Money, Credit and Banking 38(6), 1574-1597.

Anil Kayshap and Jeremey Stein (1993). "Monetary Policy and Bank Lending." National Bureau of Economics Research Working Paper 4317.

Anil Kayshap, Jeremey Stein and David Wilcox (1994). "Monetary Policy and Credit Conditions: Evidence from the Composition of External Finance." American Economic Review 83(1) 78-98.

Nobuhiro Kiyotaki and John Moore (2008). "Liquidity, Business Cycles, and Monetary Policy." manuscript.

Tommaso Monacelli (2009). "New Keynesian Models, Durable Goods, and Collateral Constraints." Journal of Monetary Economics 56, 242-254.

Hashem Peseran and Yongcheol Shin (1998). "Generalized Impulse Response Analysis in Linear Multivariate Models, Economics Letters 58(1), 17-29.

Federico Ravenna and Carl Walsh (2006). "Optimal Monetary Policy with the Cost Channel." Journal of Monetary Economics 53, 199-216. 
Joseph Stiglitz and Andrew Weiss (1981). "Credit Rationing in Markets with Imperfect Information." American Economics Review 71(3) 393-410. 


\begin{tabular}{|r|c|c|c|}
\hline & CAPUT & BAATEN & TIGHT \\
\hline CAPUT & & 6.29 & 43.91 \\
& & $(0.615)$ & $(0.000)$ \\
\hline BAATEN & 10.95 & & 32.80 \\
& $(0.205)$ & & $(0.000)$ \\
\hline \multirow{2}{*}{ TIGHT } & 10.10 & 2.93 & \\
& $(0.258)$ & $(0.938)$ & \\
\hline
\end{tabular}

Table 1

Table 1 shows $\chi^{2}$ values and p-values in parentheses for Wald exclusion tests for Granger causality including 8 lags. Dependent variables are in the column on the left, and the null hypothesis is no causality by the variable in the top row.

\begin{tabular}{|r|c|c|c|c|}
\hline & RGDP & OPH & BAATEN & TIGHT \\
\hline RGDP & & 26.66 & 9.34 & 37.70 \\
& & $(0.000)$ & $(0.053)$ & $(0.000)$ \\
\hline OPH & 23.01 & & 4.93 & 16.94 \\
& $(0.000)$ & & $(0.295)$ & $(0.002)$ \\
\hline BAATEN & 8.95 & 3.14 & & 14.25 \\
& $(0.062)$ & $(0.534)$ & & $(0.0065)$ \\
\hline TIGHT & 8.53 & 5.34 & 6.87 & \\
& $(0.074)$ & $(0.246)$ & $(0.142)$ & \\
\hline
\end{tabular}

Table 2

Table 2 shows $\chi^{2}$ values and p-values in parentheses for Wald exclusion tests for Granger causality including 4 lags. Dependent variables are in the column on the left, and the null hypothesis is no causality by the variable in the top row. 


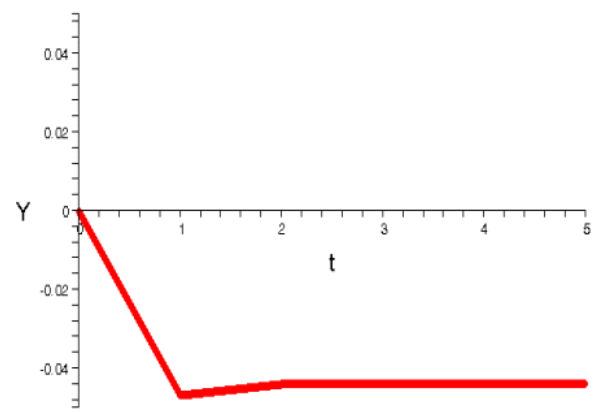

Figure 1

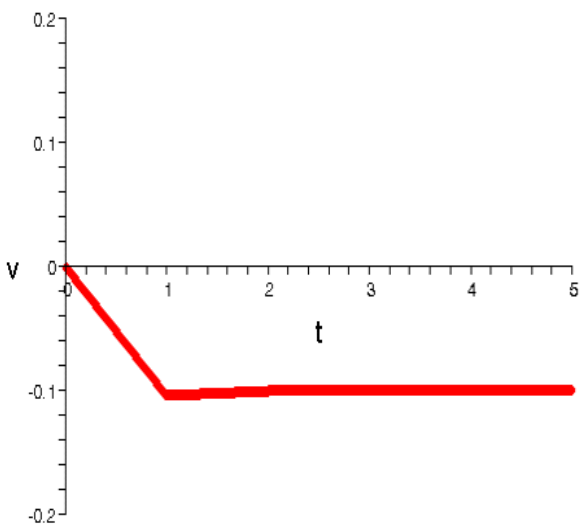

Figure 3

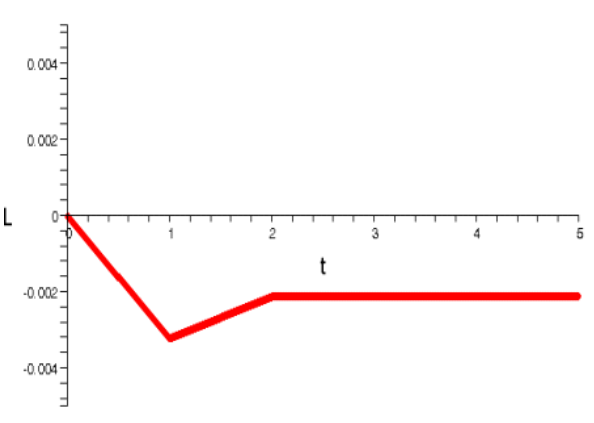

Figure 2

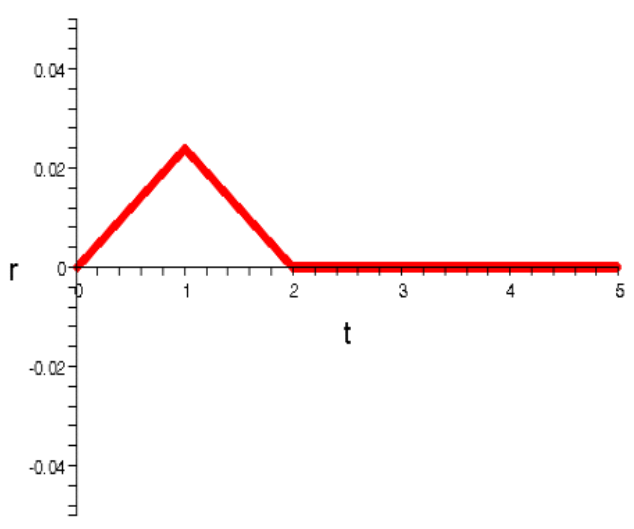

Figure 4

Responses to an increase in the credit market stress parameter $\tau$ 
Response to Generalized One S.D. Innovations \pm 2 S.E.

Response of CAPUT to BAATEN

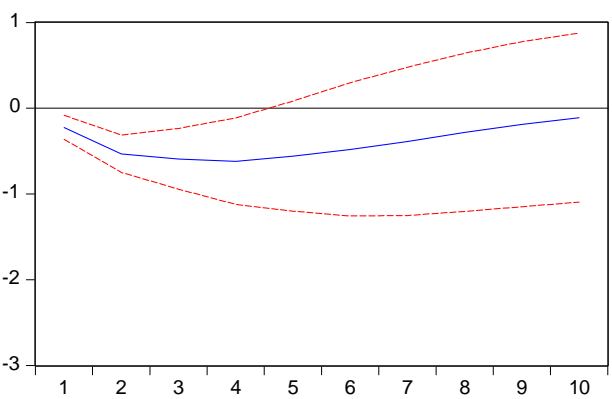

Response of BAATEN to CAPUT

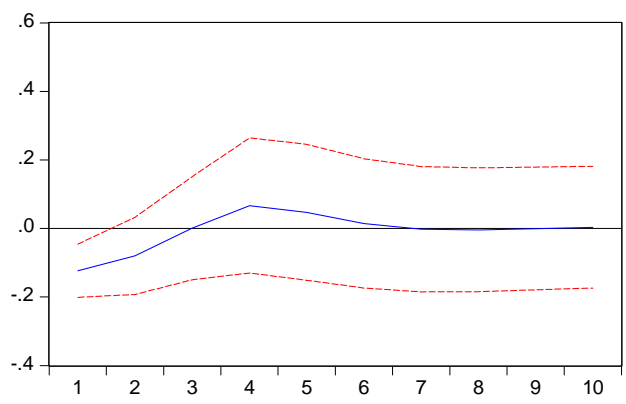

Response of TIGHT to CAPUT

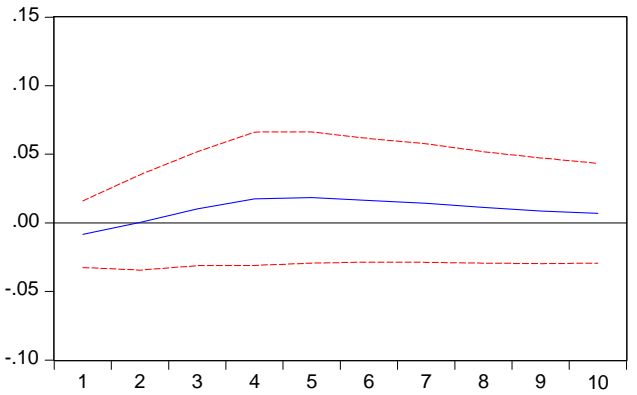

Response of CAPUT to TIGHT

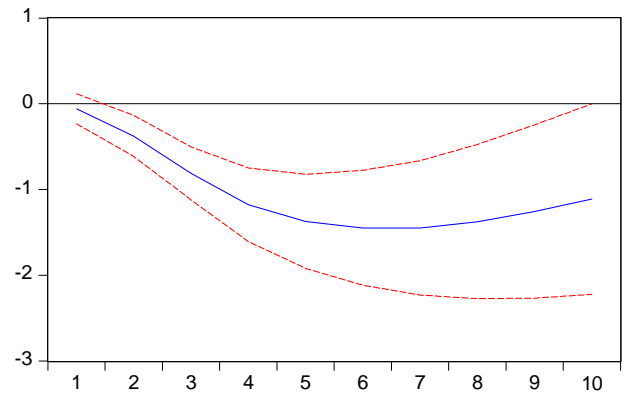

Response of BAATEN to TIGHT
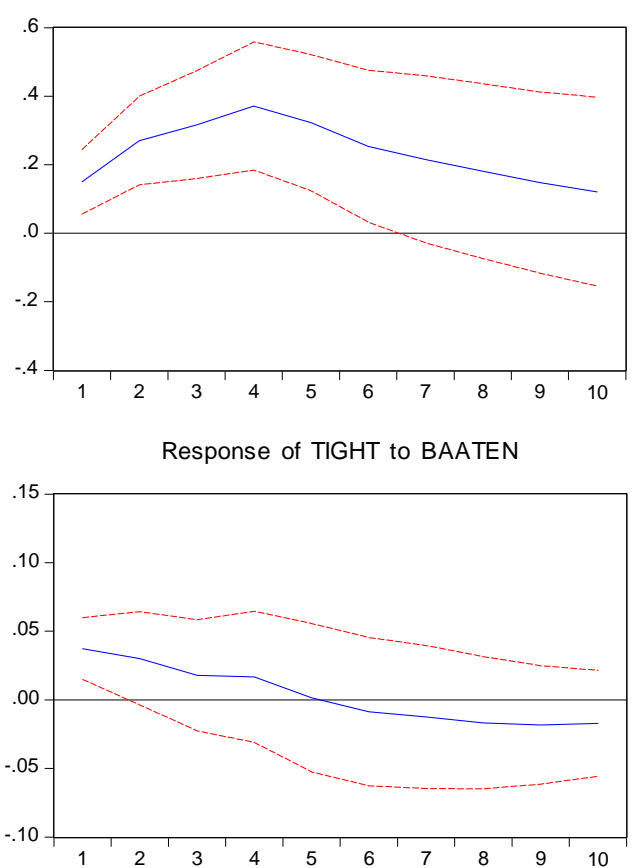

Figure 5: VAR with Table 1 variables 
Variance Decomposition \pm 2 S.E.

Percent CAPUT variance due to BAATEN

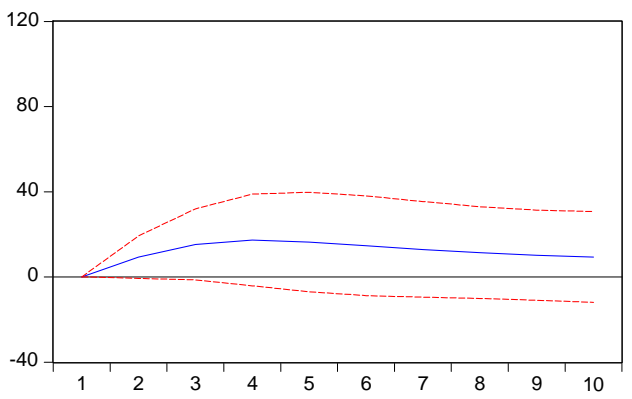

Percent BAATEN variance due to CAPUT
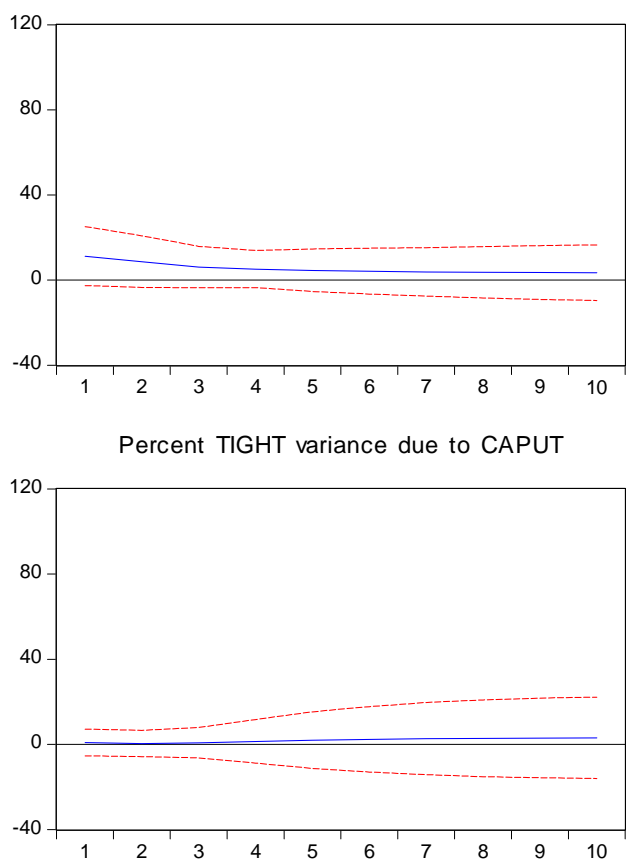

Percent CAPUT variance due to TIGHT

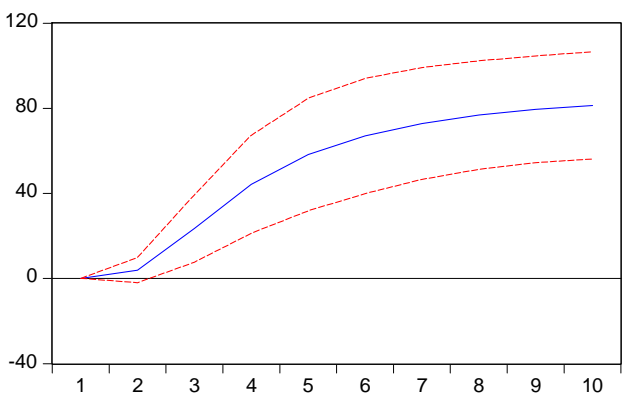

Percent BAATEN variance due to TIGHT

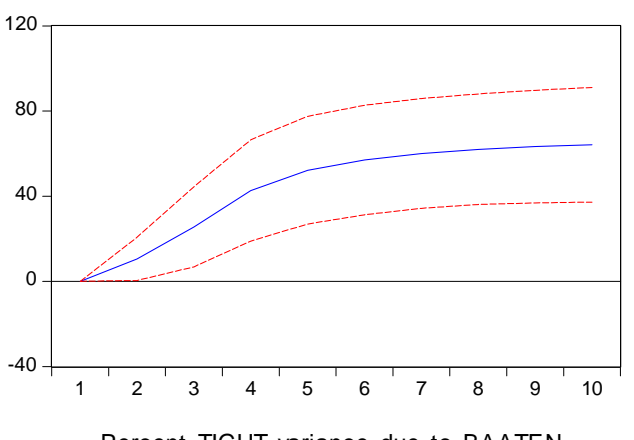

Percent TIGHT variance due to BAATEN

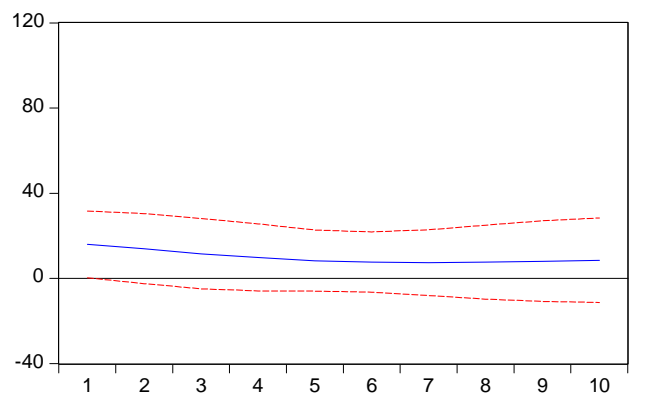

Figure 6: VAR with Table 1 variables 
Response to Generalized One S.D. Innovations \pm 2 S.E.
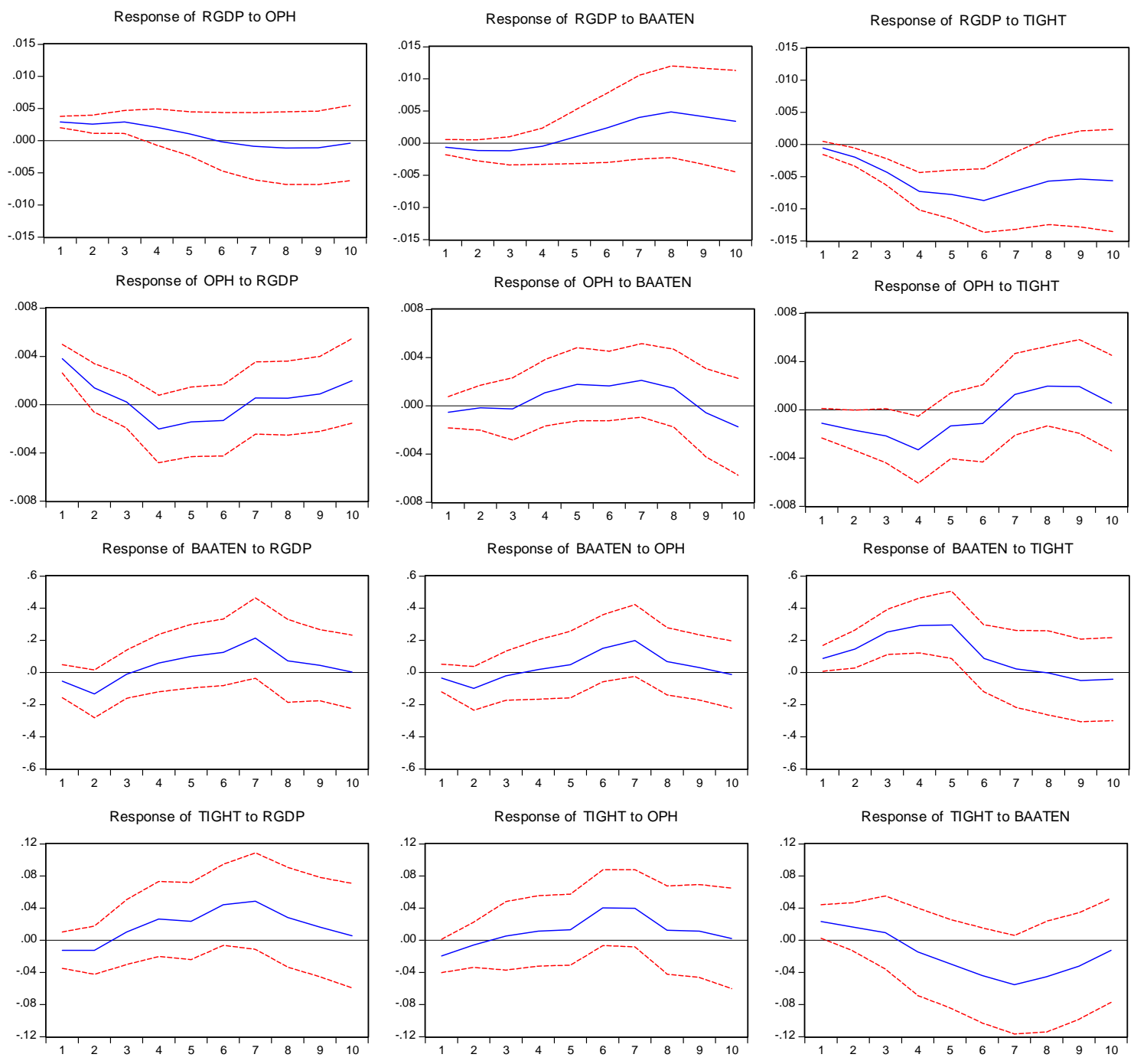

Figure 7: VAR with Table 2 variables 
Variance Decomposition \pm 2 S.E.

Percent RGDP variance due to OPH

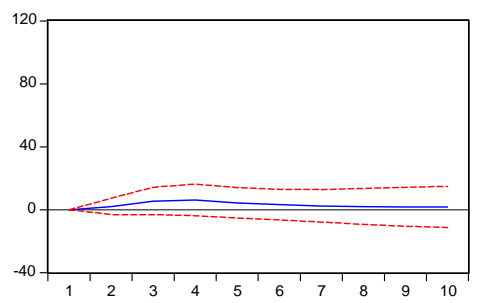

Percent $\mathrm{OPH}$ v ariance due to RGDP

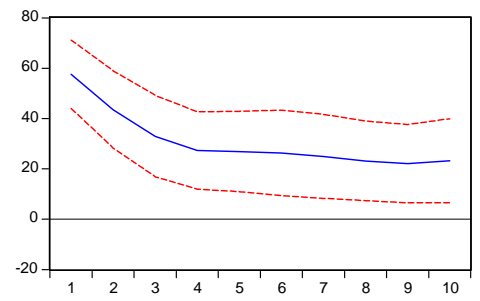

Percent BAATEN variance due to RGDP

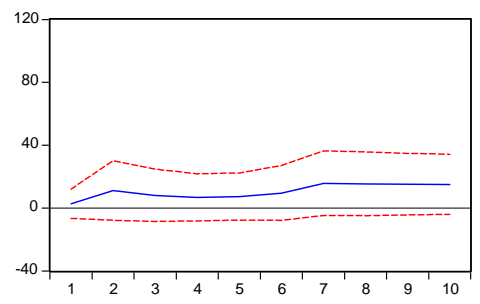

Percent TIGHT v ariance due to RGDP

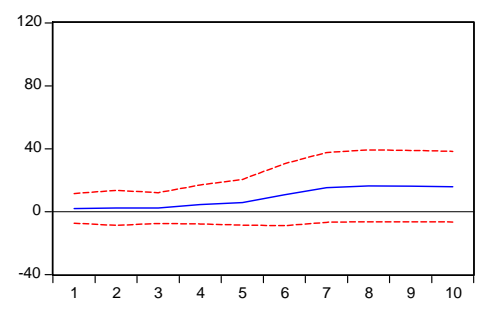

Percent RGDP v ariance due to BAATEN

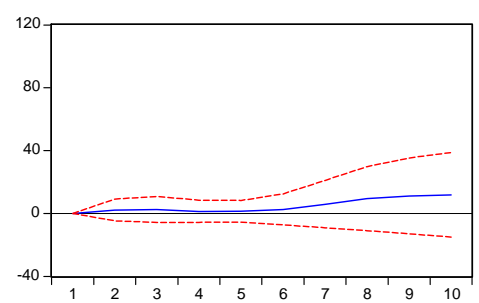

Percent OPH variance due to BAATEN

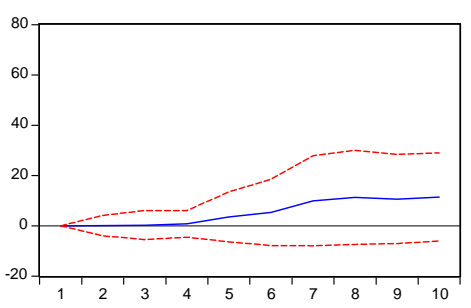

Percent BAATEN variance due to $\mathrm{OPH}$

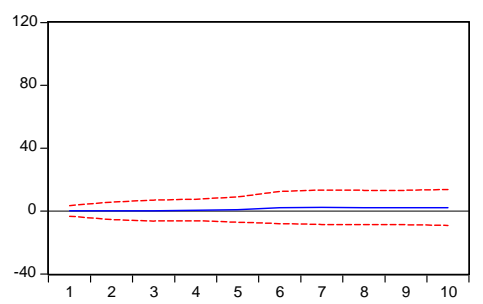

Percent TIGHT variance due to $\mathrm{OPH}$

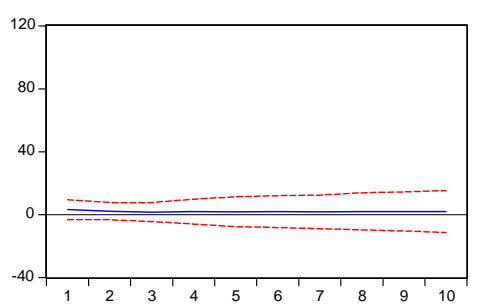

Percent RGDP variance due to TIGHT

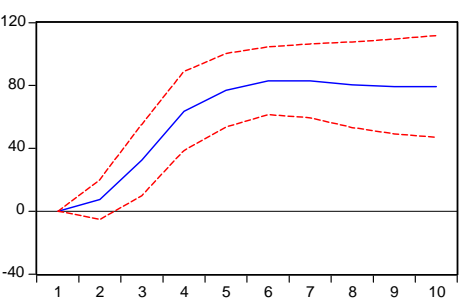

Percent OPH variance due to TIGHT

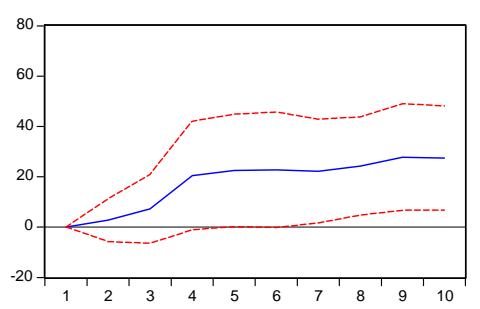

Percent BAATEN variance due to TIGHT

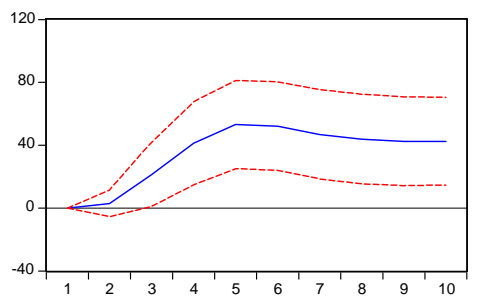

Percent TIGHT v ariance due to BAATEN

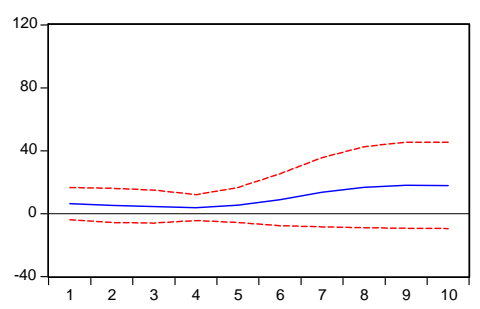

Figure 8: VAR with Table 2 variables 